\title{
Mesorhizobium alhagi sp. nov., isolated from wild Alhagi sparsifolia in north-western China
}

\author{
Correspondence \\ Ge Hong Wei \\ weigehong@yahoo.com.cn
}

\author{
Wei-Min Chen, ${ }^{1,2}$ Wen-Fei Zhu, ${ }^{1}$ Cyril Bontemps, ${ }^{2}$ J. Peter W. Young ${ }^{2}$ \\ and Ge Hong Wei ${ }^{1}$
}

${ }^{1}$ College of Life Sciences, Shaanxi Key Laboratory of Molecular Biology for Agriculture, Northwest A \& F University, Yangling Shaanxi 712100, PR China

${ }^{2}$ Department of Biology, University of York, PO Box 373, York YO10 5YW, UK

\begin{abstract}
Eleven strains that formed symbiotic root nodules on Alhagi sparsifolia, designated previously as genospecies II, were identified as a new lineage of Mesorhizobium (Alphaproteobacteria) that could be differentiated from all previously recognized species of the genus Mesorhizobium by using 16S rRNA gene sequences ( $<97.8 \%$ similarity), DNA-DNA hybridization $(<45 \%)$, dnaJ, $d n a K, \operatorname{rec} A, g \ln A$, nifH, nod $A$ and nod $C$ gene sequences, fatty acid profiles $\left(\mathrm{C}_{18: 1} \omega 7 c, 35 \% ; 11-\right.$ methyl $\left.\mathrm{C}_{18: 1} \omega 7 c, 30 \%\right)$ and numerical taxonomy. These strains are therefore considered to represent a novel species, for which the name Mesorhizobium alhagi sp. nov. is proposed, with isolate CCNWXJ12-2 ${ }^{\top}\left(=\operatorname{ACCC} 15461^{\top}=\mathrm{HAMBI} 3019^{\top}\right)$ as the type strain.
\end{abstract}

In north-western China, many legumes grow in poor soils and are dependent on a nitrogen-fixing symbiosis with rootnodule bacteria (rhizobia). Several novel rhizobial taxa have been described from this region: the genus Sinorhizobium (Chen et al., 1988) and species Mesorhizobium tianshanense (Chen et al., 1995), Mesorhizobium amorphae (Wang et al., 1999), Sinorhizobium xinjiangense (Chen et al., 1988; Peng et al., 2002), Sinorhizobium kummerowiae (Wei et al., 2003), Rhizobium yanglingense (Tan et al., 2001), Rhizobium indigoferae (Wei et al., 2002) and Rhizobium loessense (Wei et al., 2003). In this paper we describe some isolates from the legume Alhagi sparsifolia, which grows wild in this region. They represent a novel species of Mesorhizobium, a genus that was first defined by Jarvis et al. (1997) and which included 15 recognized species at the time of writing.

In a previous study, we characterized 33 rhizobia isolated from Alhagi sparsifolia that fell into three genospecies by using restriction analysis and sequencing of the rrs (smallsubunit rRNA), dnaK and dnaJ genes (Wei et al., 2009). Their symbiosis-related nodA and nodC genes also indicated their distinctness from previously described rhizobia. In this paper, we considered genospecies II, which included the largest number of strains, and present additional data comprising sequences of two additional core genes ( $\mathrm{rec} A$ and

The GenBank/EMBL/DDBJ accession numbers for the sequences reported in this paper are FJ481873-FJ481890.

Trees based on $\operatorname{rec} A, g \ln A$ and $n i f H$ genes showing the relationships among the novel isolates and recognized Mesorhizobium species, a transmission electron micrograph of a cell of strain CCNWXJ12-2 ${ }^{\top}$ and a table showing the major fatty acids of strain CCNWXJ12-2 ${ }^{\top}$ and recognized Mesorhizobium species are available as supplementary material with the online version of this paper. $g \ln A)$ and an additional symbiosis-related gene (nifH), fatty acid profile, DNA-DNA relatedness and numerical taxonomy based on phenotypic features.

The 16S rRNA gene sequences of six strains of genospecies II, including strain CCNWXJ12-2 ${ }^{\mathrm{T}}$, were identical and formed a novel branch within the genus Mesorhizobium (Wei et al., 2009; Fig. 1). They shared less than $97.8 \%$ sequence similarity with all recognized Mesorhizobium species (the most similar being Mesorhizobium loti LMG $6125^{\mathrm{T}}$ ), $96.0 \%$ with the genus Sinorhizobium and $93.1 \%$ with Rhizobium.

Nucleotide sequences of $\operatorname{rec} A, \operatorname{gln} A$ and nifH of $\operatorname{six}$ representative Mesorhizobium alhagi sp. nov. strains were amplified and sequenced (Turner \& Young, 2000; Gaunt et al., 2001; Laguerre et al., 2001), and aligned using CLUSTAL_X v.1.81 (Thompson et al., 1997). Phylogenies were constructed by using the neighbour-joining method with the Kimura two-parameter distance correction and 1000 bootstrap replicates using PHYLO_WIN (Galtier et al., 1996), and maximum-likelihood with the GTR model and 100 bootstrap replicates using PhyML (Guindon et al., 2005).

The phylogenetic tree based on 440 bp of the $\operatorname{rec} A$ gene clearly differentiated the six genospecies II strains from other Mesorhizobium (Supplementary Fig. S1a, available in IJSEM Online). They formed a clade with two subclades corresponding to the two sampling sites. Strain CCNWXJ12-2 ${ }^{\mathrm{T}}$ shared more than $99.7 \%$ sequence similarity with the other isolates from Alaer (CCNWXJ05-2, CCNWXJ12-1 and CCNWXJ05-1) and 96.6\% sequence similarity with isolates CCNWAX44-1 and CCNWAX33-1 from Anxi. Similarity to recognized Mesorhizobium species, however, was always less than $92.5 \%$. The $\operatorname{gln} A$ tree 


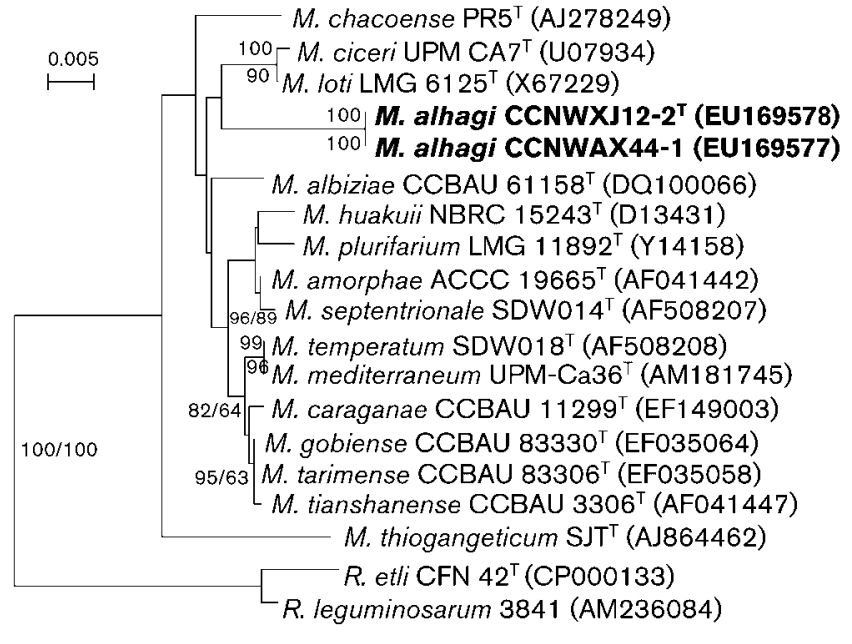

Fig. 1. Phylogeny based on $16 \mathrm{~S}$ rRNA gene sequences, showing the relationships among the novel isolates and recognized Mesorhizobium species. Bootstrap percentages greater than $60 \%$ are indicated for phylogenies constructed by using neighbour-joining (above) and maximum-likelihood (below). GenBank accession numbers are shown in parentheses. $M$, Mesorhizobium; $R$, Rhizobium. Bar, 0.005 nucleotide substitutions per site.

(Supplementary Fig. S1b) was very similar: the sequence of strain CCNWXJ12-2 ${ }^{\mathrm{T}}$ was identical to those of CCNWXJ05-2, CCNWXJ12-1 and CCNWXJ05-1, and had $96.2 \%$ similarity to those of CCNWAX44-1 and CCNWAX33-1, but only $90.3-92.2 \%$ to recognized Mesorhizobium species.

Sequences of nodA and nodC genes have been described previously (Wei et al., 2009): most Alhagi sparsifolia symbionts harboured closely related nodA and nodC genes that formed a new lineage. Within genospecies II, the distinction between Alaer and Anxi strains was maintained, although it was much less marked than for the core genes described above. For the nitrogenase gene nifH, which is involved in the symbiosis but frequently has a different phylogenetic history to the nodulation genes, the distinction between Alaer and Anxi strains was more marked, though the two groups still shared $97.1 \%$ sequence identity and were closest neighbours to each other (Supplementary Fig. S1c). However, unlike the core genes, though, the divergence between the nifH genes of genospecies II and those of other mesorhizobia was quite limited.

Total DNA was extracted from the strains tested and reference strains using the method of Marmur (1961). The $\mathrm{G}+\mathrm{C}$ content of DNA was measured using the thermal denaturation method of Marmur \& Doty (1962) and with $E$. coli $\mathrm{K}-12$ as a standard. DNA-DNA relatedness was determined using the spectrophotometric method of De Ley et al. (1970). The DNA G+C content of strain CCNWXJ12-2 ${ }^{\mathrm{T}}$ was $60.4 \mathrm{~mol} \%$ (Table 1 ), which was within the range reported for Mesorhizobium (59-64 mol\%) (Jarvis et al., 1997), and $T_{\mathrm{m}}$ was $78{ }^{\circ} \mathrm{C}$. The DNA-DNA relatedness of CCNWXJ12-2 ${ }^{\mathrm{T}}$ with the other members of genospecies II ranged from 90.8 to $100 \%$, but was less than $44.3 \%$ with any recognized Mesorhizobium species. Therefore, the strains in genospecies II can be regarded as representing a single novel species even though two subgroups were formed in the phylogenetic trees of housekeeping genes.

Fatty acid methyl esters were extracted and measured for CCNWXJ12-2 ${ }^{\mathrm{T}}$ by using the standard protocol as recommended by Hewlett Packard (Supplementary Table S1). Based on the fatty acid content, strain CCNWXJ12-2 ${ }^{\mathrm{T}}$ should be assigned to Mesorhizobium as it lacked $\mathrm{C}_{20: 3} \omega 6,9,12$ cis and summed feature $3\left(\mathrm{C}_{12: 0}\right.$, unknown ECL $10.928, \mathrm{C}_{16: 1}$ iso $\left.1 / \mathrm{C}_{14: 0} 3-\mathrm{OH}\right)$ and possessed iso$\mathrm{C}_{17: 0}$ fatty acids (Tighe et al., 2000). Strain CCNWXJ12-2 ${ }^{\mathrm{T}}$ differed from recognized Mesorhizobium species based on the high concentrations of $\mathrm{C}_{18: 1} \omega 7 c, 11$-methyl $\mathrm{C}_{18: 1} \omega 7 c$, $\mathrm{C}_{20: 1} \omega 7 c$ and a relatively high concentration of $\mathrm{C}_{17: 0}$ iso.

One hundred and fifty-three phenotypic features covering utilization of sole carbon and nitrogen sources, resistance to antibiotics, tolerance to dyes and chemicals, tolerance to various concentrations of $\mathrm{NaCl}$, temperature and $\mathrm{pH}$ ranges for growth, and other tests useful for diagnostic purposes with rhizobia were tested for these strains. Phenotypic features were analysed by using the unweighted pair group method with arithmetic averages (UPGMA) (Sneath \& Sokal, 1973). The eleven isolates fell into one cluster at $85 \%$ similarity level and were further divided into two subgroups, one group consisting of seven isolates from Alaer, and the other four isolates from Anxi (Fig. 2). Thus the phenotypic features reveal the same split into two subgroups that was apparent from the gene sequences. The distinctive features of the representative strains are shown in Table 2 and additional features are presented in the description of the novel species.

In nodulation tests, all 11 strains tested formed pink or brown nodules on the roots of Alhagi sparsifolia, which indicated that nodules were effective for nitrogen fixation, and no nodules formed on the uninoculated control plants in all experiments. In cross-infection tests using legumes that can be found in the sampling areas, CCNWXJ12-2 $2^{\mathrm{T}}$ could nodulate Sophora alopecuroides, Glycyrrhiza inflata, Medicago sativa, Indigofera endecaphylla, Vicia cracca and Sophora flavescens, but not Cassia tora or Vigna sesquipedalis. This indicates that strain CCNWXJ12-2 ${ }^{\mathrm{T}}$ has a wide host range, even though isolates with similar nodA and nod $C$ genes have not yet been reported from any host other than Alhagi sparsifolia.

The novel species can be clearly differentiated from other species in the genus by using both genetic and phenotypic methods, including sequences of core genes ( $r r s, r e c A, g \ln A$, $d n a K$ and $d n a J$ ) and symbiosis genes (nifH, nodA and nodC), fatty acid composition and DNA-DNA hybridization. Therefore the 11 strains are considered to represent a novel species for which the name Mesorhizobium alhagi sp. nov. is proposed. 
Table 1. Strains used in this study and DNA-DNA relatedness among strains representing the candidate species and the type strains of some recognized species in the genus Mesorhizobium

ND, Not determined.

\begin{tabular}{|c|c|c|c|c|c|}
\hline Strain & Host plant & Geographical origin & $T_{\mathrm{m}}$ & $\begin{array}{c}\text { DNA G + C } \\
\text { content } \\
(\mathrm{mol} \%)\end{array}$ & $\begin{array}{l}\text { DNA-DNA relatedness } \\
\text { with strain } \\
\text { CCNWXJ12-2 }^{\mathrm{T}}(\%)\end{array}$ \\
\hline CCNWXJ12-2 $2^{\mathrm{T}}$ & Alhagi sparsifolia & Alaer, Xinjiang, China & 78.0 & 60.4 & 100 \\
\hline CCNWXJ05-2 & Alhagi sparsifolia & Alaer, Xinjiang, China & 78.0 & 60.4 & 97.2 \\
\hline CCNWXJ12-1 & Alhagi sparsifolia & Alaer, Xinjiang, China & 77.8 & 59.9 & 100 \\
\hline CCNWXJ36-1 & Alhagi sparsifolia & Alaer, Xinjiang, China & 77.6 & 59.5 & 91.0 \\
\hline CCNWXJ05-1 & Alhagi sparsifolia & Alaer, Xinjiang, China & 78.0 & 60.4 & 96.8 \\
\hline CCNWXJ02-1 & Alhagi sparsifolia & Alaer, Xinjiang, China & 78.2 & 60.8 & 94.6 \\
\hline CCNWXJ12-3 & Alhagi sparsifolia & Alaer, Xinjiang, China & 79.0 & 62.4 & 93.9 \\
\hline CCNWAX44-1 & Alhagi sparsifolia & Anxi, Gansu, China & 79.0 & 62.4 & 90.7 \\
\hline CCNWAX23-1 & Alhagi sparsifolia & Anxi, Gansu, China & 79.4 & 63.3 & 97.9 \\
\hline CCNWAX33-1 & Alhagi sparsifolia & Anxi, Gansu, China & 79.4 & 63.3 & 97.9 \\
\hline CCNWAX39-1 & Alhagi sparsifolia & Anxi, Gansu, China & 79.4 & 63.3 & 90.8 \\
\hline M. temperatum SDW $018^{\mathrm{T}}$ & Astragalus adsurgens & Liaoning, China & $\mathrm{ND}$ & $\mathrm{ND}$ & 15.3 \\
\hline M. plurifarium LMG $11892^{\mathrm{T}}$ & Acacia senegal & Senegal & ND & ND & 0.6 \\
\hline M. amorphae ACCC $19665^{\mathrm{T}}$ & Amorpha fruticosa & Beijing, China & ND & ND & 9.7 \\
\hline M. loti NZP2213 ${ }^{\mathrm{T}}$ & Lotus corniculatus & New Zealand & $\mathrm{ND}$ & ND & 34.1 \\
\hline M. huakuii CCBAU2609 ${ }^{\mathrm{T}}$ & Astragalus sinicus & Nanjing, China & ND & ND & 44.3 \\
\hline M. ciceri USDA $3383^{\mathrm{T}}$ & Cicer arietinum & Spain & ND & ND & 4.9 \\
\hline M. septentrionale SDW014 ${ }^{\mathrm{T}}$ & Astragalus adsurgens & Liaoning, China & ND & ND & 2.2 \\
\hline M. albiziae CCBAU $61158^{\mathrm{T}}$ & Albizia kalkora & Sichuan, China & ND & ND & 37.8 \\
\hline M. chacoense LMG $19008^{\mathrm{T}}$ & Prosopis alba & Argentina & ND & ND & 27.1 \\
\hline M. mediterraneum USDA $3392^{\mathrm{T}}$ & Cicer arietinum & Spain & ND & ND & 34.4 \\
\hline M. tianshanense CCBAU $3306^{\mathrm{T}}$ & Glycyrrhiza uralensis & Xingjiang, China & ND & ND & 34.8 \\
\hline
\end{tabular}

\section{Description of Mesorhizobium alhagi sp. nov.}

Mesorhizobium alhagi (al.ha'gi. N.L. gen. n. alhagi of Alhagi, a genus of leguminous plants, referring to the host from which the type strain was isolated).

Gram-negative, non-spore-forming rods, aerobic, motile, $0.5-0.7 \mu \mathrm{m}$ wide by $1.3-1.5 \mu \mathrm{m}$ long (Supplementary
Fig. S2). Colonies on YMA (10.0 g mannitol, $3.0 \mathrm{~g}$ yeast extract, $0.25 \mathrm{~g} \mathrm{~K}_{2} \mathrm{HPO}_{4}, 0.2 \mathrm{~g} \mathrm{MgSO}_{4} .7 \mathrm{H}_{2} \mathrm{O}, 0.1 \mathrm{~g} \mathrm{NaCl}$, $20 \mathrm{~g}$ agar, $1000 \mathrm{ml}$ distilled water; $\mathrm{pH}$ 6.8-7.0) are white, opaque, circular and convex with diameter of 1-2 mm within 7 days at $28{ }^{\circ} \mathrm{C}$. Generation time ranges from 4.8 to $6.6 \mathrm{~h}$ in TY broth (5.0 g tryptone, $3.0 \mathrm{~g}$ yeast extract, $0.7 \mathrm{~g}$ $\mathrm{CaCl}_{2} \cdot 2 \mathrm{H}_{2} \mathrm{O}, 1000 \mathrm{ml}$ distilled water; $\mathrm{pH}$ 6.8-7.0). Produces

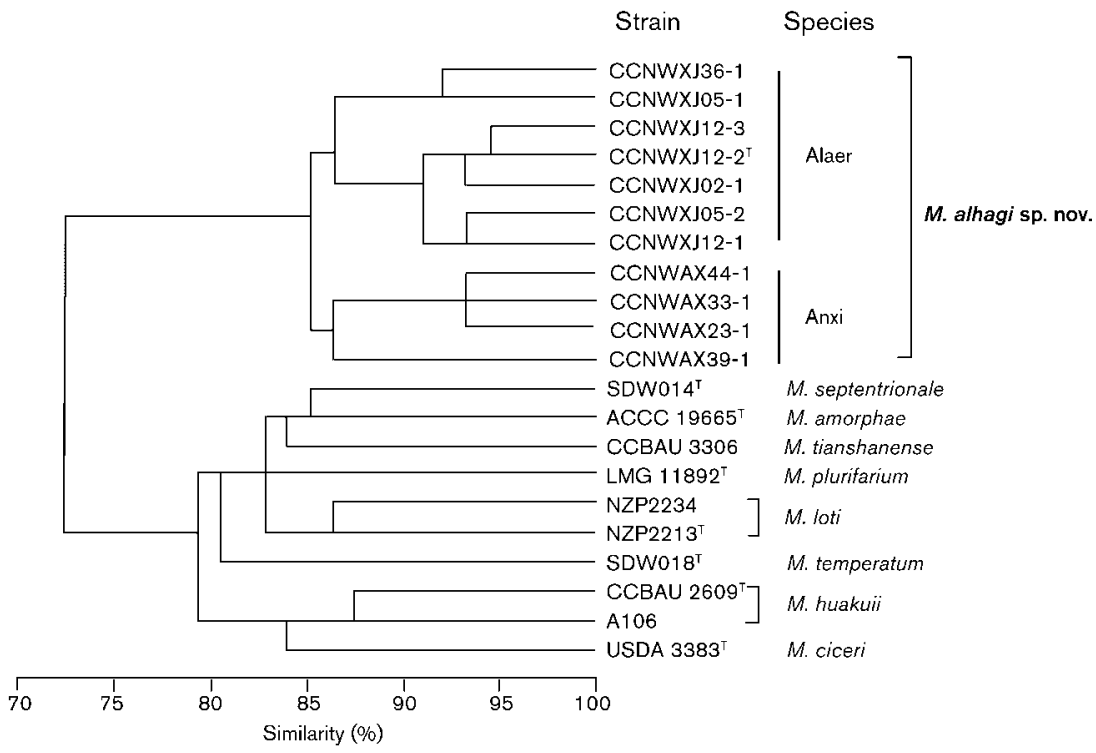

Fig. 2. Dendrogram based on the results of numerical taxonomy showing the phenotypic similarities among the rhizobial isolates and reference strains. Clustering analysis was performed using the UPGMA method. 
Table 2. Distinctive features of strains of Mesorhizobium alhagi sp. nov. and recognized species of the genus Mesorhizobium

Strains: 1, M. alhagi sp. nov. CCNWXJ12-2 ${ }^{\mathrm{T}}$; 2, M. alhagi CCNWAX44-1; 3, M. ciceri USDA 3383 ${ }^{\mathrm{T}}$; 4, M. chacoense LMG 19008 ${ }^{\mathrm{T}}$; 5, M. huakuii CCBAU $2609^{\mathrm{T}}$; 6, M. albiziae CCBAU $61158^{\mathrm{T}}$; 7, M. amorphae ACCC $19665^{\mathrm{T}}$; 8, M. loti NZP 2213 ${ }^{\mathrm{T}}$; 9, M. mediterraneum USDA $3392^{\mathrm{T}}$; 10 , M. tianshanense CCBAU $3306^{\mathrm{T}}$; 11, M. septentrionale SDW014 ${ }^{\mathrm{T}}$; 12 , M. temperatum SDW018 ${ }^{\mathrm{T}}$; 13, M. plurifarium LMG $11892^{\mathrm{T}}$. + , Growth or resistant; -, no growth or sensitive.

\begin{tabular}{|c|c|c|c|c|c|c|c|c|c|c|c|c|c|}
\hline Characteristic & 1 & 2 & 3 & 4 & 5 & 6 & 7 & 8 & 9 & 10 & 11 & 12 & 13 \\
\hline \multicolumn{14}{|l|}{$\begin{array}{l}\text { Utilization as sole carbon } \\
\text { source }\end{array}$} \\
\hline Inositol & + & + & + & + & + & + & + & + & + & + & + & + & + \\
\hline D-Fructose & + & + & + & + & + & + & + & - & + & + & + & + & - \\
\hline Maltose & + & + & + & - & + & - & + & + & + & - & + & - & + \\
\hline L-Rhamnose & + & + & + & - & + & - & - & + & + & - & + & + & + \\
\hline Sodium citrate & + & + & - & - & - & - & + & - & - & - & - & - & + \\
\hline Sodium hippurate & - & - & - & - & + & - & - & - & - & - & + & - & + \\
\hline Sodium succinate & + & + & + & - & - & + & + & + & - & + & + & - & + \\
\hline D-Sorbitol & + & + & + & - & + & - & + & + & - & + & + & + & + \\
\hline Sodium tartrate & + & - & - & + & - & - & - & - & - & - & - & - & - \\
\hline D-Aspartate & - & - & + & - & + & + & + & + & - & - & + & - & + \\
\hline L-Cystine & + & + & + & - & + & + & + & + & - & + & - & - & + \\
\hline L-Lysine & + & + & + & + & + & + & + & + & - & - & - & + & + \\
\hline L-Phenylalanine & + & + & + & - & + & + & + & + & + & + & + & + & + \\
\hline DL-Histidine & - & - & - & - & - & - & - & - & - & - & + & - & - \\
\hline Glycine & + & + & - & - & - & - & - & - & + & + & + & + & - \\
\hline \multicolumn{14}{|l|}{ Growth at: } \\
\hline pH 5 & - & - & + & - & - & - & - & - & - & - & - & - & - \\
\hline $\mathrm{pH} 10$ & + & + & - & - & - & - & - & - & - & - & - & - & - \\
\hline $1 \% \mathrm{NaCl}$ & + & + & + & - & + & - & - & - & - & - & - & - & - \\
\hline \multicolumn{14}{|l|}{ Resistance to $\left(\mu \mathrm{g} \mathrm{ml}^{-1}\right)$ : } \\
\hline Bromothymol blue (0.2\%) & - & - & + & + & + & + & + & - & + & + & + & + & + \\
\hline
\end{tabular}

acid on YMA and utilizes sodium citrate, D-sorbitol, rhamnose, L-arabinose, $\mathrm{D}$-xylose and galactose as sole carbon source. Does not utilize sodium oxalate, glycogen or sodium hippurate as sole carbon source, or utilize DL-histidine as sole nitrogen source. Growth occurs on YMA at $\mathrm{pH} 10.0,1 \%$ $\mathrm{NaCl}$ and with $0.1 \%$ neutral red and $0.1 \% \mathrm{NaNO}_{2}$. Sensitive to streptomycin, gentamicin sulfate, amikacin sulfate $(50 \mu \mathrm{g}$ $\mathrm{ml}^{-1}$ ) and $5 \mu \mathrm{g}$ ampicillin $\mathrm{ml}^{-1}$. The DNA G $+\mathrm{C}$ content of the type strain is $59.5-63.3 \mathrm{~mol} \%$.

The type strain, CCNWXJ12-2 $2^{\mathrm{T}} \quad\left(=\mathrm{ACCC} \quad 15461^{\mathrm{T}}\right.$ $=$ HAMBI $3019^{\mathrm{T}}$ ), was isolated from a root nodule of Alhagi sparsifolia in Alaer, Xinjiang, China.

\section{Acknowledgements}

This work was supported by projects from the National Science Foundation of China (30670372, 30630054), RFDP (20050712013) and PCSIRT, and by the UK Natural Environment Research Council (NE/B505046/1). We are grateful to Dr Kristina Lindström and Professor Jiang for deposition of the strain in the culture collections.

\section{References}

Chen, W. X., Yan, G. H. \& Li, J. L. (1988). Numerical taxonomic study of fast-growing soybean rhizobia and proposal that Rhizobium fredii be assigned to Sinorhizobium gen. nov. Int J Syst Bacteriol 38, 392397. 
Chen, W. X., Wang, E. T., Wang, S., Li, Y., Chen, X. \& Li, Y. (1995). Characterization of Rhizobium tianshanense sp. nov., a moderately and slow growing root nodule bacterium isolated from an arid saline environment in Xinjiang, People's Republic of China. Int J Syst Bacteriol 45, 153-159.

De Ley, J., Cattoir, H. \& Reynaerts, A. (1970). The quantitative measurement of DNA hybridization from renaturation rates. Eur $J$ Biochem 12, 133-142.

Galtier, N., Gouy, M. \& Gautier, C. (1996). SEAVIEW and PHYLO_WIN: two graphic tools for sequence alignment and molecular phylogeny. Comput Appl Biosci 12, 543-548.

Gaunt, M. W., Turner, S. L., Rigottier-Gois, L., Lioyd-Macgilp, S. A. \& Young, J. P. W. (2001). Phylogenies of atpD and recA support the small subunit rRNA-based classification of rhizobia. Int J Syst Evol Microbiol 51, 2037-2048.

Ghosh, W. \& Roy, P. (2006). Mesorhizobium thiogangeticum sp. nov., a novel sulfur-oxidizing chemolithoautotroph from rhizosphere soil of an Indian tropical leguminous plant. Int J Syst Evol Microbiol 56, 9197.

Guindon, S., Lethiec, F., Duroux, P. \& Gascuel, O. (2005). PHYML Online - a web server for fast maximum likelihood-based phylogenetic inference. Nucleic Acids Res 33, 557-559.

Jarvis, B. D. W., van Berkum, P., Chen, W. X., Nour, S. M., Fernandez, M. P., Cleyet-Marel, J. C. \& Gillis, M. (1997). Transfer of Rhizobium loti, Rhizobium huakuii, Rhizobium ciceri, Rhizobium mediterraneum, and Rhizobium tianshanense to Mesorhizobium gen. nov. Int J Syst Bacteriol 47, 895-898.

Laguerre, G., Nour, S. M., Macheret, V., Sanjuan, J., Drouin, P. \& Amarger, N. (2001). Classification of rhizobia based on nodC and nifH gene analysis reveals a close phylogenetic relationship among Phaseolus vulgaris symbionts. Microbiology 147, 981-993.

Marmur, J. (1961). A procedure for the isolation of deoxyribonucleic acid from microorganisms. J Mol Biol 3, 208-218.

Marmur, J. \& Doty, P. (1962). Determination of the base composition of deoxyribonucleic acid from its thermal denaturation temperature. J Mol Biol 5, 109-118.

Peng, G. X., Tan, Z. Y., Wang, E. T., Reinhold-Hurek, B., Chen, W. F. \& Chen, W. X. (2002). Identification of isolates from soybean nodules in
Xinjiang Region as Sinorhizobium xinjiangense and genetic differentiation of S. xinjiangense from S. fredii. Int J Syst Evol Microbiol 52, 457462.

Sneath, P. H. A. \& Sokal, R. B. (1973). Numerical Taxonomy. The Principles and Practice of Numerical Classification. San Francisco: W. H. Freeman.

Tan, Z. Y., Kan, F. L., Peng, G. X., Wang, E. T., Reinhold-Hurek, B. \& Chen, W. X. (2001). Rhizobium yanglingense sp. nov., isolated from arid and semi-arid regions in China. Int J Syst Evol Microbiol 51, 909914.

Thompson, J. D., Gibson, T. J., Plewniak, F., Jeanmougin, F. \& Higgins, D. G. (1997). The CLUSTAL_X windows interface: flexible strategies for multiple sequence alignment aided by quality analysis tools. Nucleic Acids Res 25, 4876-4882.

Tighe, S. W., de Lajudie, P., Dipietro, K., Lindström, K., Nick, G. \& Jarvis, B. D. W. (2000). Analysis of cellular fatty acids and phenotypic relationships of Agrobacterium, Bradyrhizobium, Mesorhizobium, Rhizobium and Sinorhizobium species using the Sherlock Microbial Identification System. Int J Syst Evol Microbiol 50, 787-801.

Turner, S. L. \& Young, J. P. W. (2000). The glutamine synthetases of rhizobia: phylogenetics and evolutionary implications. Mol Biol Evol 17, 309-319.

Wang, E. T., van Berkum, P., Sui, X. H., Beyene, D., Chen, W. X. \& Martínez-Romero, E. (1999). Diversity of rhizobia associated with Amorpha fruticosa isolated from Chinese soils and description of Mesorhizobium amorphae sp. nov. Int J Syst Bacteriol 49, 51-65.

Wei, G. H., Wang, E. T., Tan, Z. Y., Zhu, M. E. \& Chen, W. X. (2002). Rhizobium indigoferae sp. nov. and Sinorhizobium kummerowiae sp. nov., respectively isolated from Indigofera spp. and Kummerowia stipulaceae. Int J Syst Evol Microbiol 52, 2231-2239.

Wei, G. H., Tan, Z. Y., Zhu, M. E., Wang, E. T., Han, S. Z. \& Chen, W. X. (2003). Characterization of rhizobia isolated from legume species within the genera Astragalus and Lespedeza grown in the Loess Plateau of China and description of Rhizobium loessense sp. nov. Int J Syst Evol Microbiol 53, 1575-1583.

Wei, G. H., Chen, W. M., Young, J. P. W. \& Bontemps, C. (2009). A new clade of Mesorhizobium nodulating Alhagi sparsifolia. Syst Appl Microbiol 32, 8-16. 